\title{
Green Initiatives: A Study on Two Wheelers
}

\author{
Jai Jayant ${ }^{* 1}$, SuchitaVishwakarma ${ }^{2}$ and Ashok Sengupta ${ }^{3}$ \\ 1.* Assistant Professor, Himgiri Zee University, Dehradun, (Uttra Khand), India. \\ 2 and 3. Assisant Professor, School of Management Sciences, Lucknow-226501 (U.P.), India.
}

\section{Publication Info}

\section{Article history :}

Received : $17^{\text {th }}$ July., 2018

Accepted : 05 ${ }^{\text {th }}$ Dec., 2018

DOI : 10.18090/samriddhi.v10i02.8

Keywords :

Green Marketing, Green Product, Purchase Decisions.

*Corresponding author :

Jai Jayant

e-mail : jai.jayant110@gmail.com

\begin{abstract}
Indian economic development has brought with itself various challenges and health hazards. Rise of deadly diseases, are result of ecological degradation. The transportation system is one major catalyst to urban ecological imbalance. Epidemiological studies have shown that, air pollution causes thousands of health problems leading to number of deaths in Indian cities. Other effects of ecological disturbance include global warming and increase in natural calamities which are now forcing us to take major decisions related to conservation of environment. Keeping in view, there is an urgent need of the entire stakeholder to take remedial actions to reduce the pace of further degradation of existing environment. Since transportation is the back bone of any economy so this sector needs serious attention regarding formulation of necessary rules and regulations, strict enforcement of emission norms for vehicles, proper traffic planning, use of clean fuel etc., and also to make aware the public about necessity of sustainable environment in cities.
\end{abstract}

Thus, this study is an attempt to know the understanding of public about green marketing initiatives and green vehicles. The customer is key to any marketing effort. An effort has been taken to understand, if the customer is aware about eco-friendly two wheeler and is ready to make changes in his purchase behavior accordingly. For the same a structured questionnaire had been designed to collect information from 135 educated residents of Lucknow.

\section{INTRODUCTION}

$\mathrm{T}_{\mathrm{r}}$ he word Green marketing first evolved as ecological marketing during a workshop conducted by American Marketing Association in 1975. In the workshop ecological marketing was defined as "study of positive and negative aspects of marketing on pollution, energy depletion and nonenergy resource depletion(Henion and Kinnear 1979).

Green, environmental and eco-marketing are few of terminologies used as new marketing approaches which focuses on adjusting, adapting or enhancing existing marketing perspectives and practice for the benefit of sustainable development. In other words these approaches seek to address the lack of fit between marketing as it is currently practiced and the ecological and social realities.

McDaniel and Rylander (1993),explained green marketing as the marketer's efforts in developing strategies targeting the eco-friendly consumer. Polonsky (1994) defined green marketing as all activities designed to generate and facilitate any exchanges intended to satisfy human needs or wants, with minimal unfavorable impact on natural environment". 
Environmentally-responsible or "green" marketing is thus a business practice that takes into account consumer concerns about promoting, preserving and conserving of the natural environment. Green marketing campaigns highlights the features of product/service that is critical for achieving sustainability. These features or characteristics can be anything like reducing waste during packaging, improving energy efficiency, reduction in use of chemicals, decrease in toxicemissions etc. However a study conducted by Polonsky(1994) concluded that for general public green marketing refers only to the endorsement/ advertising/promotion of products with environmental characteristics.
In the last few years India has overtaken China and emerged as the world's biggest market for twowheelers. A total of 17.7 million two-wheelers were sold in India during 2016-17, which means more than 48,000 units every day. While China sold approximately 16.8 million units during the same period.Two Wheelers sales have registered a growth of $14.80 \%$ in April-March 2018 over April-March 2017. Within the Two Wheelers segment, Scooters and Motorcycles grew by $19.90 \%$ and $13.69 \%$ respectively, while Mopeds declined by (-) 3.48\% in April-March 2018 over April-March 2017.

\section{Automobile Industry in India}

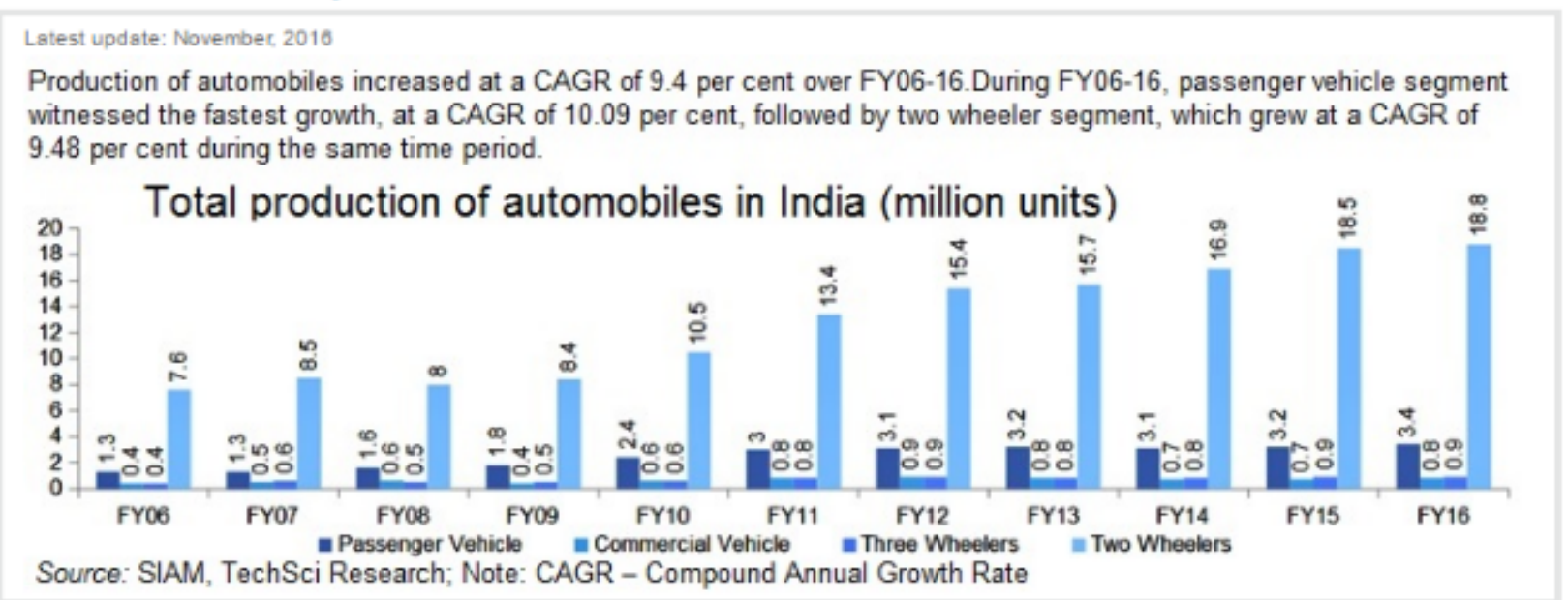

Fig.1: Total Production of Automobiles in India

The credit to the rise in sales goes to rising incomes, growing infrastructure and increase in women commuters. Moreover, it becomes easy for commuters to escape out of the traffic chaos by the use of two wheelers. An official of Honda, stated that particularly in their scooter market, the share of women is approximately $35 \%$.

Thus the question arises that whether enough efforts have been taken by all the stakeholders to understand the interdependency of pollution and vehicles and to be more specific two wheelers.
In the recent past Indian government has taken few initiatives in this regards by imposing stringent regulation for frequent pollution checks of vehicles. Now, BS IV standards have also been laid down for all vehicle sales and registrations in April 2017. The regulation establishes the first ever evaporative emission standards for two- and threewheelers. BS VI standards, which apply in April 2020, largely align emission limits for twowheeled vehicles with European standards (although they are slightly more relaxed). 
But the cause of concern still sustains. Despite these government initiatives, it needs to be clearly understood that the pace at which the government and other stakeholders are adopting the green practices is very slow. And if this continues then probably it would be very late, in terms of achieving sustainability.

Thus this study is an effort to understand how much is the general public aware and ready to accept the green vehicles. The study also tries to compare the cost effectiveness of green vehicles with the petrol version to have a closer evaluation between the two.

\section{LITERATURE REVIEW}

Breno and David (2010) conducted research on Green Operations Initiatives in the Automotive Industry. The purpose of study was to focus on investigating and benchmarking green operations initiatives in the automotive industry documented in the environmental reports of selected companies. The findings however were restricted to world's three major car manufacturers.

Patrali, (2009) studied the green brand extension strategy and examined the current and prospective consumer perceptions, purchase intent due to green branding.

Tyagi Himani (2013)in her paper described green marketing as the best strategy to sustain in today's world. Sharma Avinish (2013) said that, it is only through "Go Green" concept that the environmental sustainability can be achieved and the harm done to the world through traditional vehicles by emitting harmful emissions can be reduced. Studies reveal that electric bikes have come into consideration as fuel price is increasing and playing a major role especially in country like India.

Srivastava Mukesh, Malik Komal, Kumar Rajendra (2016) mentioned about the consumer's concern and practice of purchasing environmentally friendly products. The study revealed that the actual number of consumer's purchasing and using green products is relatively low and thus this gap needs be exploited for future market opportunity. Marketers, government agencies, environmental agencies and media, must promote green products and emphasize their importance for sustainability. This will also help in building a strong positive image and in enhancing the goodwill of the companies amongst the consumers.

Various studies have revealed that one of the most important restrains to development of green products is the lack of consumer trust and the lack of information (Cervellon et al. 2010; Yiridoe et al., 2005).

Ali et.al. (2011) conducted a study on Pakistani consumer to know their attitude and purchase intentions for green products and found that consumers have a positive attitude towards green products, but are reluctant due to their high prices and poor quality as compared to traditional products. Shafaat and Sultan (2012) stated that there was a need to determine the best path forward by developing efficient green products.

\section{RESEARCH METHODOLOGY}

This research is descriptive in nature. Data has been collected both from primary and secondary sources. Convince sampling techniques is used to collect responses from 135 educated people of Lucknow city, who can be assumed to understand the importance of ecological sustainability. Primary data is collected by structured questionnaire. Whereas secondary data was collected from published journals and websites.

\section{OBJECTIVES OF RESEARCH}

1. To study the consumer's awareness regarding green product.

2. To find out consumer's attitude towards environment. 
3. To understand how much consumer are to get influenced my green marketing.

\section{ANALYSIS}

Awareness ab out Global warming

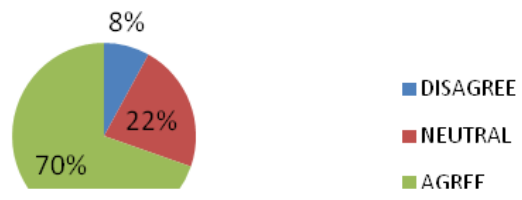

Fig.1: Awareness of Global Warming

Questions were asked from the respondents and out of total 135 responses received $70 \%$ respondents stated that they were aware about global warming fig. 1 . The same could also be justified by the various options that they choose in terms of meaning of word "green" asked in the questionnaire. Most of the respondent had clear understanding of "Green marketing".

Vehicular emissions as a prime source of pollution

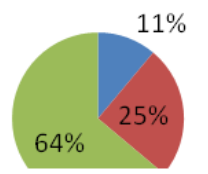

- DISAGREE

- NEUTRAL $\because \mathrm{AGRFF}$

Fig.2: Vehicular emissions percentage

According to fig.2, 64\% respondents agreed that vehicular emissions are a prime source of pollution.

Perception regarding CNG as environmental friendly auto fuel
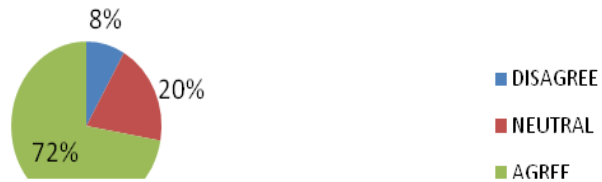

Fig.3: Perception towards Environmental friendly fuels.

Fig. 3 concludes that $72 \%$ respondents agree that CNG is the most environment friendly auto fuel while $20 \%$ were not very sure about the emissions and pollution effect of $\mathrm{CNG}$ as auto fuel.
Environment friendliness of existing two wheelers in market

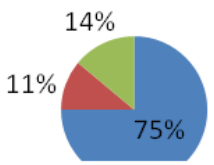

DISAGREE - NEUTRAL $=$ AGRFF

Fig.4: Environment Friendliness

As per fig. 4, $75 \%$ of respondents are aware that most of the two wheelers available in market are not environment friendly and have high level of harmful emissions which disturb the ecological balance. While $25 \%$ respondents were either not sure or disagreed with the question being asked.

Awareness regarding Govt. rules for vehicular emissions

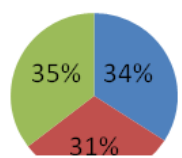

DISAGREE

- NEUTRAL

I AGREE

Fig.5: Awareness About Govt Rules

Contradictory to the previous responses, only $35 \%$ respondents stated that they were fully aware of Govt. rules on vehicular pollution and agreed with its importance, while the majority totaling to approx. $65 \%$ respondents were not fully aware of govt. rules on vehicular pollution. This in itself is a major cause of concern. This response justified the finding of study conducted by Cervellon et al. (2010).

Company's adherence to green standards

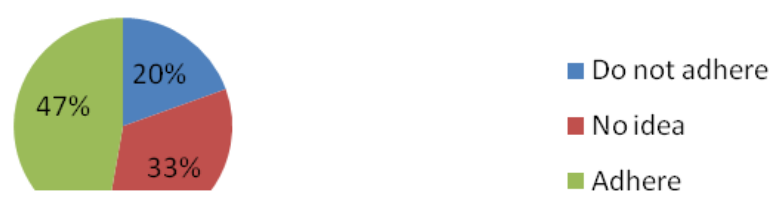

Fig.6: Company's Adherence

Fig. 6 states that $47 \%$ respondents have the opinion that two- wheeler manufacturing companies strictly follow green Standards like BS-3 and BS4 regulation while the rest that is more than $50 \%$ were either not fully aware of govt. rules or 
disagreed to companies' adherence to norms. Hence, this response also justified the need to spread awareness of rules and regulation regarding vehicular emissions.

Perception regarding price of Green vehicle in comparison to petrol two wheelers

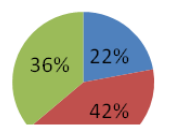

- Less expensive

No Idea

More expensive

Fig.7: Perception regarding price

Fig. 7 shows that according to $36 \%$ respondents, price of green two wheelers are more than petrol two wheelers while $22 \%$ respondent's disagreed that the price of green two wheelers are more than petrol two wheelers. However, $42 \%$ respondents did not have any idea about the price. This means that majority of the people did not have correct perception or confusions regarding the price of green vehicles.

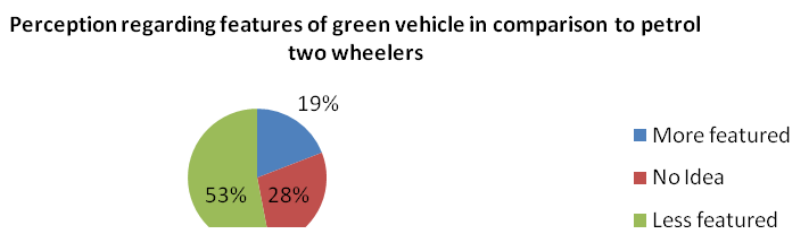

Fig. 8: Perception regarding green two wheelers

Fig. 8 reflects that $53 \%$ respondents believed that green two wheelers have less features in comparison to petrol two wheelers. This meant that features could be one of the reasons of low or slow acceptability for green two wheelers.

Rumning \& maintenance cost of green two wheelers economic in comparison to petrol

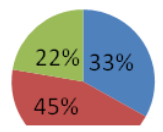

DISAGREE

- NEUTRAL

AGRFF

Fig.9: Regarding Running and maintenance cost
The responses collected showed that $22 \%$ respondents perceived running and maintenance cost of green two wheelers to be less in comparison to petrol two wheelers while $33 \%$ respondents disagreed that running and maintenance cost of green two wheelers is not more in comparison to petrol two wheelers. $45 \%$ respondents lacked information regarding running and maintenance cost of both types of two wheelers.

Seen people driving green two wheelers or in advertisements

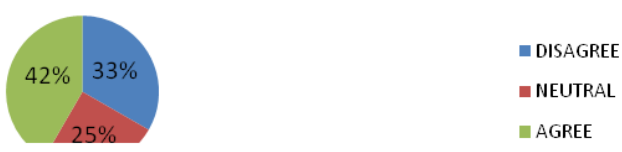

Fig.10: Advertisement of two wheeler

On enquiring whether the respondents have ever seen the green two wheeler either physically or in advertisement, $42 \%$ respondents agreed while the major chunk could not recall if they have ever seen (Fig: 10).

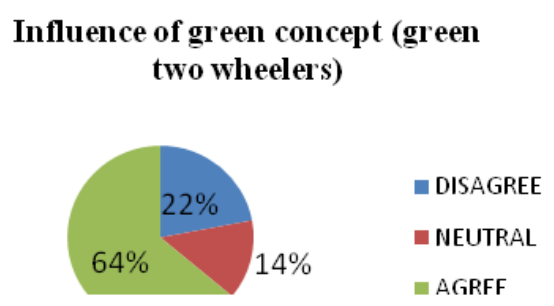

Fig.11: Influence of green concept

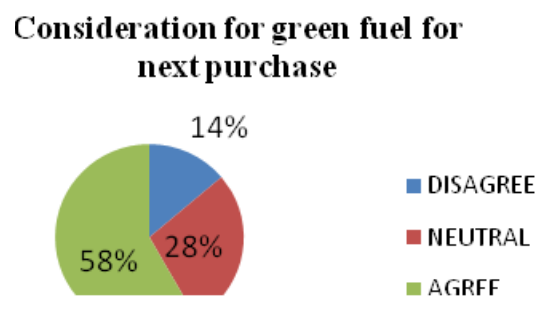

Fig.12: Future plan for green fuel

Fig. 11, shows that $64 \%$ respondents agreed that they got influenced with the concept of green two wheelers and would like to consider during the next purchase. While $36 \%$ respondents were not 
very convinced with it. The same also got justified by responses shown in Fig 12, where approx. 58\% respondent showed their willingness to switch to alternate green fuel vehicle in their next purchase.

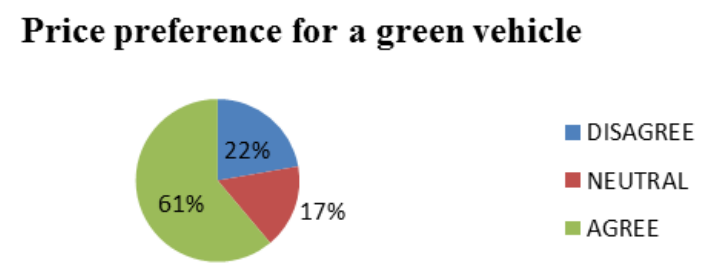

Fig.13: Price preference

\section{Ready to compromise with features for a green two wheeler}

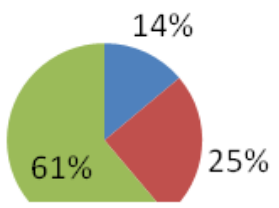

- DISAGREE
NEUTRAL
aGRFF

Fig.14: Features for Green Two wheeler

Fig. 13 and 14 shows that $61 \%$ respondents were ready to pay slightly more and also ready to compromise with certain features for a green vehicle that does not pollute the environment, while the rest were sensitive to price and features. This makes it evident that there is a huge scope and market for green two wheelers.

\section{CONCLUSION}

This paper is based on environment and people's awareness and attitude towards using two wheelers, which has less pollution. The results of analysis show that all respondents are well aware about environmental issues. Respondents also have a positive attitude towards usage of eco friendly product. Maximum respondents are willing to buy two wheelers, which have less emissions. This research indicates that demand of electric two wheelers is high in comparison to number of manufactures. Some problems which are faced by users of electric bike are: (i) recharge of batteries (recharge point) in city, (ii) problem is electric battery vehicles are not durable for long distance (iii) cost of electric vehicle is higher than petrol two wheelers. Government should initiate to promote electric vehicle and provide incentives to the manufacturers and dealers.

\section{REFERENCES}

[1] Avnish, S. (2013). Go Green With FdI In Indian Two Wheeler Automobile Industry. International Journal Of Business Management and Research (Ijbmr), 5561.

[2] Himani, T. (2013). Emerging Strategies of Green Marketing In India. Bookman International Journal Of Accounts, Economics and Business Management, 45-49.

[3] Irfan Mohmed, D. S. (2014). Green Marketing Mix Strategies Of Consumer Durables With Reference To Automobile Sector. International Journal Of Emerging Research In Management andTechnology, 55-60.

[4] Overview Of Automobile Industry In The Light Of Green.

[5] Srivastava Mukesh, M. K. (2016). Consumers' Readiness For Green Products And Its Effect On. Amity Journal Of Marketing, 93.

[6] The Indian Automotive Industry. India, Kpmg In.

[7] Mcdaniel, S., and Rylander, D. (1993). Strategic Green Marketing. The Journal Of Consumer Marketing, 10(3), 4-10.

[8] Breno Nums and David Bennett (2010), Green Operations Initiatives In The Automotive Industry, Benchmarking: An International Journal, 17 (3), 396420.

[9] Patrali Chatterjee,(2009), „Green Brand Extension Strategy And Online Communities, Journal Of Systems And Information Technology, Vol. 11 No. 4, 367-384. 
[10] Henion, Karl E., And Thomas C. Kinnear. 1976b. “A Guide To Ecological Marketing." In Karl E. Henion and Thomas C. Kinnear (Eds). Ecological Marketing. Columbus, Ohio: American Marketing Association.

[11] Ali, A., Khan, A., and Ahmed, I. (2011). Determinants Of Pakistani Consumers Green Purchase Behaviour: Some Insights From A Developing Country. International Journal of Business And Social Science, 2(3), 217-226.
[12] Shafaat, A., and Sultan A. (2012). Green Marketing. Excel International Journal Of Multidisciplinary Management studies, 2(5), 184-195.

[13] Sharma, Y. (2011). Changing Consumer Behaviour With Respect To Green Marketing-A Case Study of Consumer Durables And Retailing. International Journal Of Multidisciplinary Research, 1(4), 152162. 
